\title{
In situ acoustic and laboratory ultrasonic sound speed and attenuation measured in heterogeneous soft seabed sediments: Eel River shelf, California
}

\author{
Thomas J. Gorgas ${ }^{\mathrm{a}, *}$, Roy H. Wilkens ${ }^{\mathrm{b}}$, Shung S. Fu ${ }^{\mathrm{b}, 1}$, L. Neil Frazer ${ }^{\mathrm{a}}$, \\ Mike D. Richardson ${ }^{c}$, Kevin B. Briggs ${ }^{c}$, Homa Lee ${ }^{\mathrm{d}}$ \\ a Department of Geology and Geophysics, 1680 East West Road, University of Hawaii, Honolulu, HI 96822, USA \\ b Hawaii Institute of Geophysics and Planetology, University of Hawaii, 1680 East West Road, Honolulu, HI 96822, USA \\ c Marine Geosciences Division, Naval Research Laboratory, Stennis Space Center, MS 39529-5004, USA \\ d U.S. Geological Survey, Mail Stop 999, 345 Middlefield Road, MS 999, Menlo Park, CA 94025, USA
}

Received 2 July 1999; accepted 30 October 2000

\begin{abstract}
We compared in situ and laboratory velocity and attenuation values measured in seafloor sediments from the shallow water delta of the Eel River, California. This region receives a substantial volume of fluvial sediment that is discharged annually onto the shelf. Additionally, a high input of fluvial sediments during storms generates flood deposits that are characterized by thin beds of variable grain-sizes between the 40 - and $90-\mathrm{m}$ isobaths. The main objectives of this study were (1) to investigate signatures of seafloor processes on geoacoustic and physical properties, and (2) to evaluate differences between geoacoustic parameters measured in situ at acoustic $(7.5 \mathrm{kHz})$ and in the laboratory at ultrasonic $(400 \mathrm{kHz})$ frequencies. The in situ acoustic measurements were conducted between 60 and 100 $\mathrm{m}$ of water depth. Wet-bulk density and porosity profiles were obtained to $1.15 \mathrm{~m}$ below seafloor ( $\mathrm{m}$ bsf) using gravity cores of the mostly cohesive fine-grained sediments across- and along-shelf. Physical and geoacoustic properties from six selected sites obtained on the Eel margin revealed the following. (1) Sound speed and wet-bulk density strongly correlated in most cases. (2) Sediment compaction with depth generally led to increased sound speed and density, while porosity and in situ attenuation values decreased. (3) Sound speed was higher in coarser- than in finer-grained sediments, on a maximum average by $80 \mathrm{~m} \mathrm{~s}^{-1}$. (4) In coarse-grained sediments sound speed was higher in the laboratory $\left(1560 \mathrm{~m} \mathrm{~s}^{-1}\right)$ than in situ $\left(1520 \mathrm{~m} \mathrm{~s}^{-1}\right)$. In contrast, average ultrasonic and in situ sound speed in finegrained sediments showed only little differences (both approximately $1480 \mathrm{~m} \mathrm{~s}^{-1}$ ). (5) Greater attenuation was commonly measured in the laboratory $\left(0.4\right.$ and $\left.0.8 \mathrm{~dB} \mathrm{~m}^{-1} \mathrm{kHz}^{-1}\right)$ than in situ $\left(0.02\right.$ and $\left.0.65 \mathrm{~dB} \mathrm{~m}^{-1} \mathrm{kHz}^{-1}\right)$, and remained almost constant below $0.4 \mathrm{~m}$ bsf. We attributed discrepancies between laboratory ultrasonic and in situ acoustic measurements to a frequency dependence of velocity and attenuation. In addition, laboratory attenuation was most likely enhanced due to scattering of sound waves at heterogeneities that were on the scale of ultrasonic
\end{abstract}

${ }^{1}$ Environmental Management Division, Department of Health, State of Hawaii. 919 Ala Moana Boulevard, Suite 212, Honolulu, HI-96814, USA.

* Corresponding author. Present address: Hawaii Natural Energy Institute, University of Hawaii, 2525 Correa Rd., Honolulu, HI-96822, USA, Tel: +1-808-956-5711; Fax: +1-808-956-2336.

E-mail address: tgorgas@soest.hawaii.edu (T.J. Gorgas). 
wavelengths. In contrast, high in situ attenuation values were linked to stratigraphic scattering at thin-bed layers that form along with flood deposits. (C) 2002 Published by Elsevier Science B.V.

Keywords: Eel River; Velocity; Attenuation; Porosity; Density; Dispersion; Scattering

\section{Introduction}

The advent of technology to map the seafloor in great detail at high frequencies has sparked new interest in the acoustic properties (namely, sound speed and attenuation) of the upper few meters of seafloor sediment. However, swath mapping sonar signal returns are affected by both the morphology of the sediment-seawater interface and volume scattering from the region immediately below the seafloor (Borgeld et al., 1999). Therefore, swath-mapping measurements reveal limited detailed information about nearsurface sediments deeper than a few tenths of meters below the seafloor ( $\mathrm{m}$ bsf). Consequently, sediment geoacoustic properties have been mainly examined by laboratory measurements performed at frequencies much higher than those employed by sonar systems. The Acoustic Lance (Fu et al., 1996a) was developed to record near-surface acoustic data in situ for comparison to those measured in the laboratory at ultrasonic frequencies. Thus, Acoustic Lance measurements provide important information about in situ geoacoustic properties of the uppermost seafloor sediments and establish a link between high-frequency laboratory data and in situ conditions.

The present study, conducted in June 1996, is integrated into STRATAFORM (Strata Formation on Margins), a long-term monitoring project sponsored by the Office of Naval Research that aims to enhance the understanding of dynamic sediment transport and deposition processes along active and passive continental shelves (Nittrouer and Kravitz, 1995, 1996; Nittrouer, 1999). Our field area was the Eel River margin (Fig. 1), a continental shelf in the vicinity of the Eel River delta in northern California that was selected for the STRATAFORM program because it exhibits a sediment and lithostratigraphic texture typical of active margins around the world (Nittrouer, 1999). We focused on the measurement of sedi- ment sound speed, attenuation, and wet-bulk density to determine possible relationships between both geoacoustic and physical properties and how they relate to seafloor processes and sedimentary structure. These properties of marine sediments at the benthic boundary layer are generally controlled by the interaction of biological, biogeochemical, geological and hydrodynamic processes (Richardson et al., 1983; Briggs et al., 1985; Richardson and Briggs, 1996). Results from previous studies on the Eel margin and in similar environments concluded that biological activity could directly alter the acoustic and physical structure of the subsurface in a random fashion down to $0.3 \mathrm{~m}$ bsf (e.g., Drake, 1999; Cutter and Diaz, 2000). For example, bioturbation may disturb laminated zones that were formerly created by erosion and depositional events (Richardson and Young, 1980; Richardson, 1986; Ogston and Sternberg, 1999). Our goal was to obtain more information about these complex processes by deploying the Acoustic Lance at stations between 60 and $100 \mathrm{~m}$ of water depth and on a lateral transect along the 70-m isobath (Fig. 1). Sediments were gravity-cored simultaneously to investigate their acoustic and physical properties under laboratory conditions.

\section{Regional setting}

The sediments of our study area on the Eel River shelf consist mostly of fine-grained and cohesive muds with minute amounts of silts and sands. The stratigraphy of the active Eel margin is significantly shaped by periodic flood deposits, which are generated on average every decade during short-term discharge events (e.g., Goff et al., 1996, 1999; Wheatcroft et al., 1996, 1997; Cacchione et al., 1999). Suspended fluvial sediments are carried across- and along-shelf by strong surface and bottom currents in a northward direction 


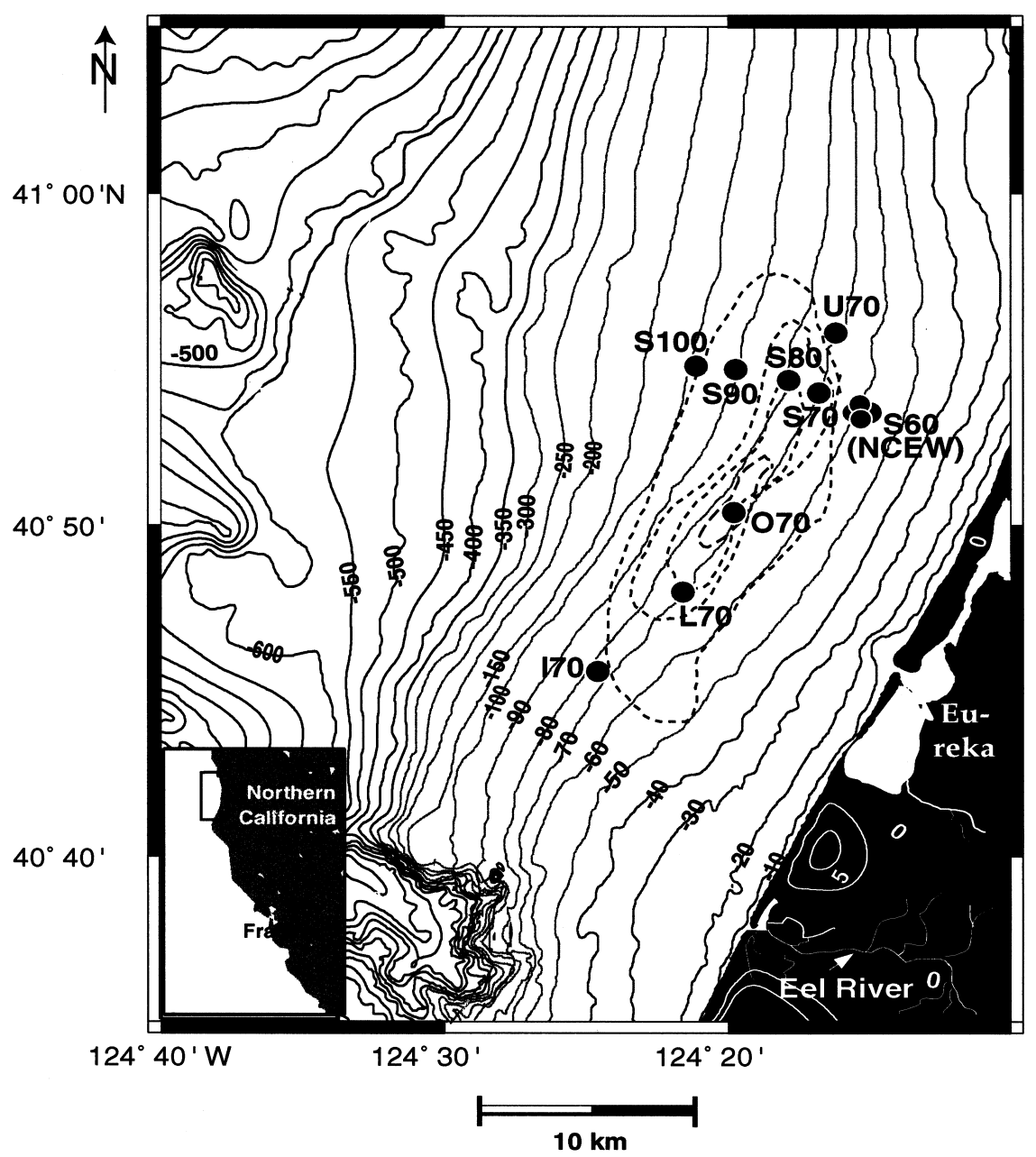

Fig. 1. Bathymetry on the Eel River shelf and the location of a flood deposit from 1995 (outlined with dotted black lines), which increases in thickness from 0.01 to $0.07 \mathrm{~m}$ across the 60- and 90-m isobaths (after Wheatcroft et al., 1996, 1997; Goff et al., 1996, 1999). All core and Lance stations are marked in the downslope and along-shelf direction.

during storm events and in a southward direction during storm-free periods, while they mix with coarser-grained shelf sediments (e.g., Drake and Cacchione, 1985; Wiberg et al., 1996; Cacchione and Drake, 1990; Cacchione et al., 1999). The bulk of discharged fluvial sediments is transported further offshore and deposited below the zone of high turbulence (Wiberg et al., 1996; Cacchione et al., 1999). Subsequently, the seafloor is significantly bioturbated over time causing a downcore coarsening of some deposits until the next flood deposit recharges this part of the shelf with more sediment (Wiberg et al., 1996; Wheatcroft et al., 1996, 1997; Drake, 1999; Cutter and Diaz, 2000). The lower strata of a flood deposit from 1995 most likely represent remnants of older flood deposits which have been partly eroded during storm periods, and reworked by biological processes (Goff et al., 1996, 1999; Borgeld et al., 1999).

Earlier coring and bathymetry work on the Eel margin confirmed that long- and short-term processes have created highly complex heterogeneous deposits (e.g., Orange, 1999; Sommerfield and Nittrouer, 1999). 
A

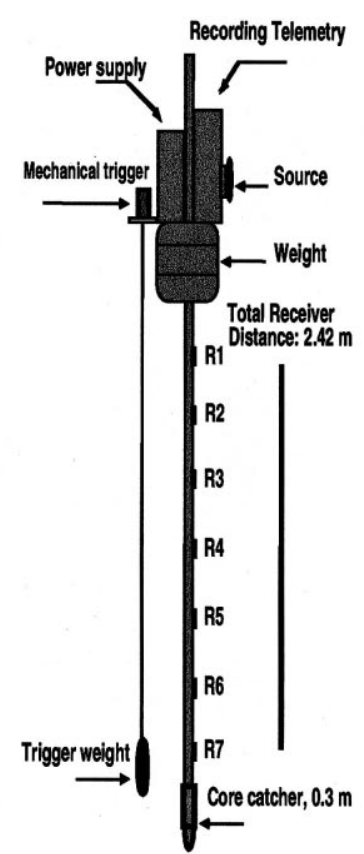

B

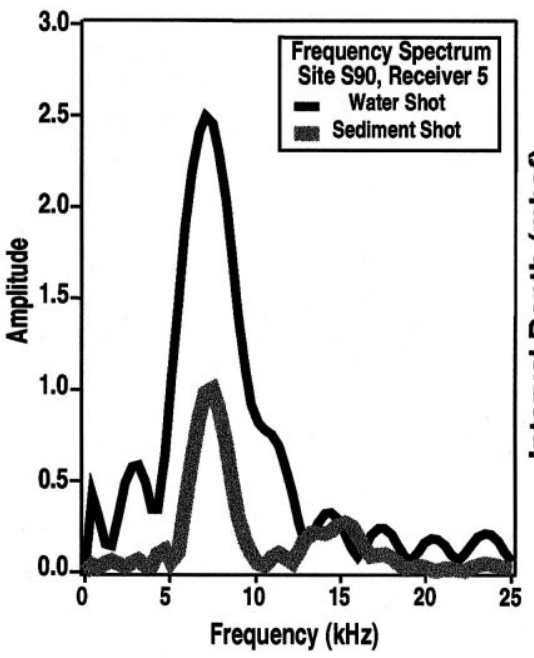

C

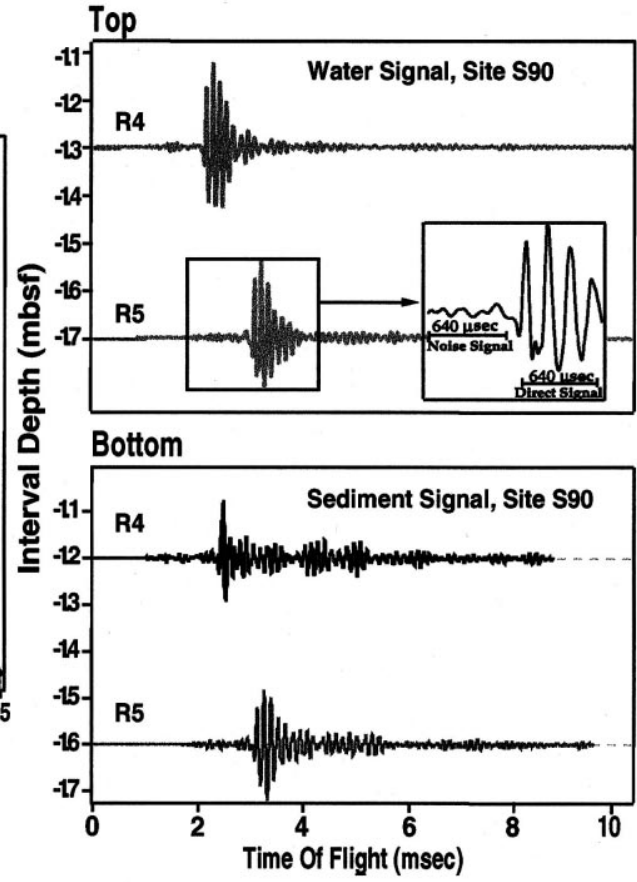

Fig. 2. Acoustic Lance configuration used for the present study (A). Frequency spectra of Lance signals at Site S90 (after Frazer et al., 1999) showed little noise contamination and a center frequency of approximately $7.5 \mathrm{kHz}$ (B). Higher amplitudes of the self-normalized acoustic signal were noticed when emitted in the water column than in the seafloor (C, top). Water reference signals obtained at Site S90 (after Frazer et al., 1999) revealed a subtle difference in frequency response of the individual transducers and different waveforms when recorded in sediments $(\mathrm{C}$, bottom).

\section{Methods}

\subsection{Lance - an in situ acoustic probe}

The Acoustic Lance (Fig. 2A) measures in situ interval sound speed and effective attenuation profiles using full-waveform records $(\mathrm{Fu}$ et al., 1996a; Frazer et al., 1999) and has been successfully deployed in a variety of unconsolidated sediments. Mid-Atlantic Ridge pelagic oozes showed low velocities corresponding to low attenuation (Fu et al., 1996a). In organic-rich, high-porosity Holocene sediments of the Baltic Sea, compressional wave sound speed was less than $1400 \mathrm{~m}$ $\mathrm{s}^{-1}$, and attenuation was high due to the presence of methane gas bubbles created by microorganisms (Fu et al., 1996b; Wilkens and Richardson, 1998). Lance operations in carbonate-rich, gas- free sediment deposits offshore of the island of Oahu, Hawaii, provided evidence for a dependence of attenuation on frequencies between 10 $\mathrm{kHz}$ and $1 \mathrm{MHz}(\mathrm{Fu}, 1998)$.

In contrast to previous Lance deployment areas where deposits were relatively homogeneous, California shelf sediments are heterogeneous (e.g., Goff et al., 1999). Therefore, a comparatively high variation in sound speed and attenuation within short horizontal distances across the shelf and with depth below seafloor was expected.

\subsection{Calculation of in situ acoustic compressional wave sound speed}

For the present study, seven receivers were mechanically fixed on a core barrel at approximately 0.4-m intervals below a broadband acoustic 
source that emitted a signal centered on $7.5 \mathrm{kHz}$ (Fig. 2A,B). Before each in situ experiment the instrument was routinely calibrated by a recording in the water column before Lance was inserted into the seafloor (Fig. 2C, top). Waveforms from this calibration allowed us to determine the exact spacing between the acoustic centers of the individual receiver elements, and then to calculate attenuation (Frazer et al., 1999). After the water calibration, the corer freefell to the seafloor and penetrated the subbottom to a depth that depended primarily on the shear strength of the sediment. In situ compressional wave sound speed was calculated from different arrival times of acoustic waves and the known separation of the acoustic centers of all Lance transducers (Fig. 2C). Signals from adjacent receivers were cross-correlated to establish an objective procedure for first arrival picking. Lance signals were recorded with a sampling rate of $10 \mu$ s and resampled by applying an FFT and zero padding in the frequency domain to twice the original length. An inverse FFT completed the interpolation and resulted in a sampling rate of $2.5 \mu$ s (Fu et al., 1996a). Thus, a sound speed resolution better than $1 \%$ was achieved.

\subsection{Calculation of in situ acoustic compressional wave attenuation}

In addition to profiling in situ compressional wave sound speed, Lance signals (Fig. 2C) were used to obtain in situ attenuation at acoustic wavelengths. The measurement of attenuation at sonic frequencies $(1-20 \mathrm{kHz})$ in the laboratory is difficult because samples of large dimension are required in order to resolve the macroscopic structure of the material at sonic wavelengths. The calculation of effective in situ attenuation from Lance records addresses this problem.

Effective attenuation comprises intrinsic and scattering attenuation. Intrinsic attenuation is a result of the conversion of elastic energy into heat, and scattering attenuation occurs when elastic waves diffract and reflect on larger particles or at boundaries and thin-bed layers. Scattering is characterized primarily by constructive and destructive interferences of wave trains. In poroelas- tic materials such as sediments, attenuation and its variation with frequency reveal information about the state of compaction, lithology, and degree of saturation. Hamilton (1972) fit the attenuation coefficient $(\alpha)$ in $\mathrm{dB} \mathrm{m}^{-1}$ for sound speed in unconsolidated surficial sediments using the equation:

$\alpha=k f^{n}$

where $k$ is a constant in $\mathrm{dB} \mathrm{m} \mathrm{m}^{-1} \mathrm{kHz}^{-1}$ when $n=1$, and $f$ denotes the frequency in $\mathrm{kHz}$. Methods to calculate the frequency dependence of attenuation have been given by several authors to suit low- and high-frequency applications (O'Connell and Budianski, 1978; Kjartansson, 1979). However, in nearly every experimental geometry attenuation is difficult to measure (Jannsen et al., 1985; Tonn, 1989; Bromirski et al., 1995; Bowles, 1997; Richardson and Briggs, 1997). The processing technique by Frazer et al. (1999), which we applied to our data, combines the standard spectral ratio method (e.g., Tonn, 1989) and Bayesian inverse theory (e.g., Tarantola, 1987).

\subsection{Calculation of laboratory ultrasonic compressional wave sound speed}

Shipboard ultrasonic experiments were conducted on sediments recovered in the plastic liners of the gravity cores. All samples were measured at 0.01-m intervals using an ultrasonic tabletop system with a source-receiver transducer pair operated at $400 \mathrm{kHz}$. Ultrasonic compressional wave sound speed in sediments $\left(c_{\mathrm{sed}}\right)$ was obtained in the laboratory by measuring the travel time of a signal, first in a reference sample containing distilled water, secondly in the cored sediments (Richardson et al., 1983), and then using:

$c_{\mathrm{sed}}=\frac{c_{\mathrm{W}}}{1-\left(\Delta t c_{\mathrm{w}} / d\right)}$

where $c_{\mathrm{w}}$ is the reference water sound speed, $d$ represents the core inside diameter, and $\Delta t$ the difference in signal arrival times through water and sediment samples. Sound speeds were adjusted to in situ conditions by applying Hamilton's velocity ratio method (Hamilton, 1971b; 
Richardson and Briggs, 1997). Ultrasonic laboratory sound speed was measured again on-shore at $0.01-\mathrm{m}$ intervals with a Multi-Sensor-Track (MST) at $500 \mathrm{kHz}$ (Boyce, 1976), which produced results almost identical to our shipboard data.

\subsection{Calculation of laboratory ultrasonic compressional wave attenuation}

The ultrasonic compressional wave attenuation coefficient $\left(\alpha_{\mathrm{sed}}\right)$ was computed by comparing voltage amplitudes of signals at $400 \mathrm{kHz}$ transmitted through both a water standard $\left(a_{\mathrm{w}}\right)$ and the cored sediments $\left(a_{\mathrm{s}}\right)$. The first three positive maximum peak amplitudes of the signals were recorded to calculate $\alpha_{\text {sed }}$ in the time domain (e.g., Richardson et al., 1983; Richardson and Briggs, 1997), using:

$\alpha_{\text {sed }}=\frac{20}{d} \log \frac{a_{\mathrm{w}}}{a_{\mathrm{s}}}$

with $d$ as the distance between the transmitter and the receiver of the system $(0.06 \mathrm{~m})$. Results were converted into $\mathrm{dB} \mathrm{m} \mathrm{m}^{-1} \mathrm{kHz}^{-1}$, equivalent to Hamilton's constant $k$, assuming the linear relationship $\alpha=k f^{1}$ (Hamilton, 1972).

\subsection{Density, porosity and mean grain size}

Wet-bulk density profiles of gravity cores were determined on shore using a gamma-ray attenuation porosity evaluator (GRAPE), which compares attenuation of gamma rays through cored sediments with attenuation through an aluminum standard (Boyce, 1976). Gravimetric determinations of sediment density and porosity on individual samples from the gravity cores were not made. However, sediment porosities were determined on shorter box core subsamples using gravimetric methods. Grain density measurements with an air-comparison pycnometer indicated an average grain density of $2.7 \mathrm{~g} \mathrm{~cm}^{-3}$. Sediment porosity of gravity cores was then calculated using average grain density of box core sediments and raw GRAPE wet-bulk density. Near-surface porosity values calculated from GRAPE scans were consistently lower than from wet-bulk density data obtained with gravimetric methods on box core samples. A wet-bulk density correction value of maximal 5\% was calculated from the difference between the two wet-bulk densities and added to porosity values that we deduced from GRAPE data.

Box-core sediment samples showed a dominance of fine-grained and cohesive sediments with a mean grain size around $7 \phi$ (Richardson et al., 2002), which corresponded to values obtained by others (e.g., Borgeld et al., 1999; Drake, 1999; Cutter and Diaz, 2000).

\section{Results}

Sediment sound speed, attenuation, wet-bulk density and porosity obtained at six sites across the shelf were selected to represent geoacoustic and physical properties of our entire study area. The presentation of data was restricted to those sites where a low noise content of the in situ acoustic signals promised most reliable results for acoustic sound speed and attenuation. Sites S60, S80, and S100 comprised the downslope transect across the $60-\mathrm{m}$ and $100-\mathrm{m}$ isobaths, while Sites I70, L70, and S70 were located along the 70-m isobath (Fig. 1). From four sub-sites that were cored at Site $\mathrm{S} 60$ within a radius of approximately $125 \mathrm{~m}$, we decided to limit ourselves to Site S60West for most of our discussion because of the most favorable signal quality. Geoacoustic data obtained at Site S90 were presented elsewhere (Frazer et al., 1999).

\subsection{Downslope properties}

Sound speed, density, porosity, and attenuation vs. penetration depth for Sites S60West, S80, and S100 are displayed in Fig. 3. In situ interval sound speed ranged between 1440 and $1490 \mathrm{~m} \mathrm{~s}^{-1}$ at the water-seafloor interface, and varied between 1505 and $1540 \mathrm{~m} \mathrm{~s}^{-1}$ at approximately $1.5 \mathrm{~m} \mathrm{bsf}$ (Fig. 3A). In situ and ultrasonic sound speed at all three sites showed similar trends with a positive gradient over most parts of the Lance and core profiles. However, in situ sound speed at Site S60West was higher between 0.25 and 0.65 

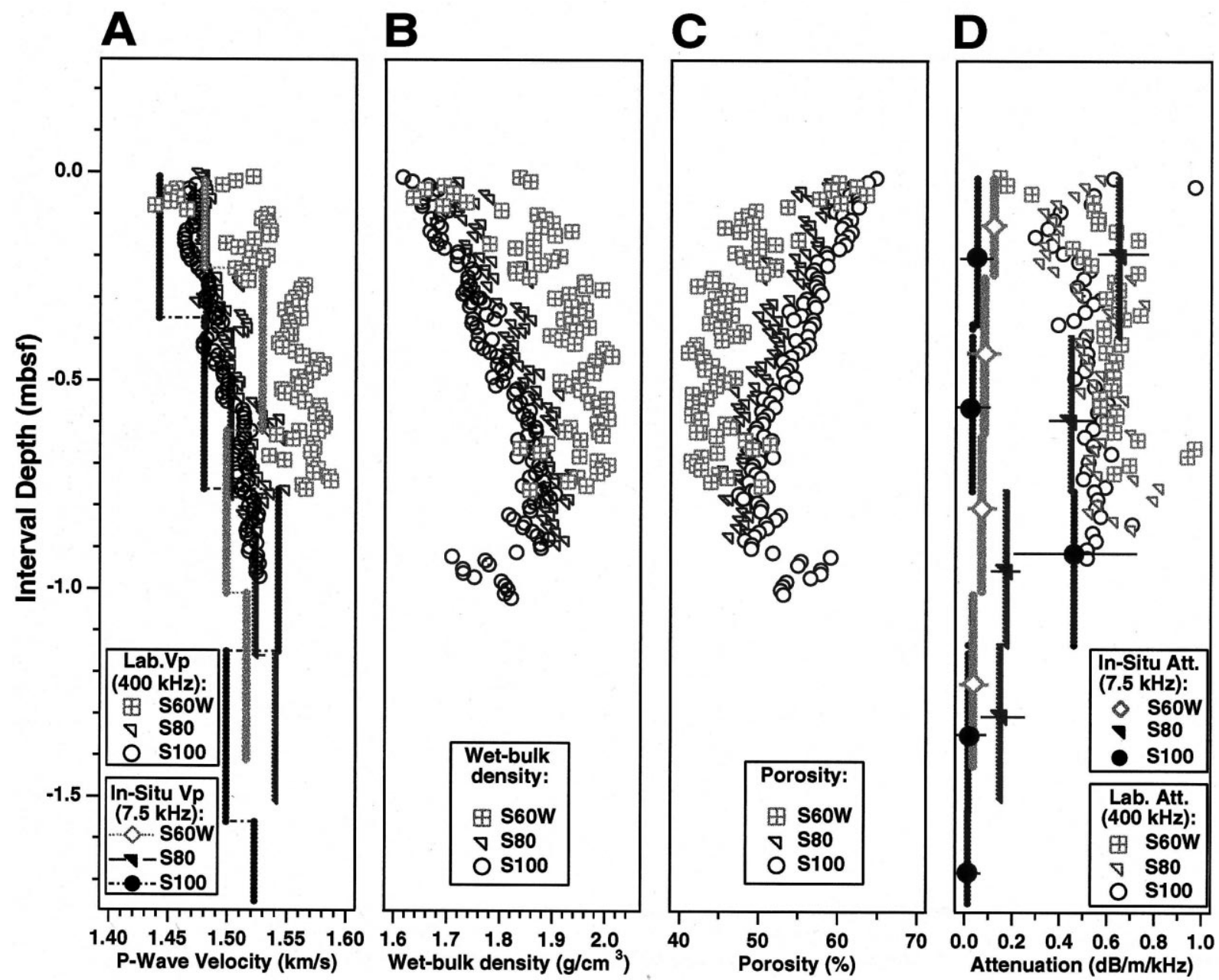

Fig. 3. Downslope variation of interval sound speed (A), wet-bulk density (B), porosity (C), and interval attenuation (D) vs. depth on the Eel River shelf. Horizontal error bars on attenuation data points were extracted from 10 best-fit inverse models (Frazer et al., 1999). Ultrasonic sound speeds and attenuation were measured in the shipboard laboratory on core samples at 400 $\mathrm{kHz}$ every $0.01 \mathrm{~m}$.

$\mathrm{m}$ bsf than at Sites $\mathrm{S} 80$ and $\mathrm{S} 100$, and showed a slight decrease below $0.65 \mathrm{~m}$ bsf. At Site S60West ultrasonic laboratory sound speed was consistently higher than corresponding in situ values over the majority of core lengths, and faster than ultrasonic sound speed obtained at Sites S80 and S100 (Fig. 3A). The difference between in situ acoustic and average laboratory ultrasonic sound speed at Site S60West was as great as $35 \mathrm{~m}$ $\mathrm{s}^{-1}$ between 0.25 and $0.65 \mathrm{~m}$ bsf.

Wet-bulk density at Sites S60West, S80 and S100 strongly correlated with sound speed in most cases (Fig. 3A,B). Maximum wet-bulk density was observed at the seafloor at Site S60West $\left(1.85 \mathrm{~g} \mathrm{~cm}^{-3}\right)$, compared to lower values found at Sites S80 and S100 (1.64 to $1.72 \mathrm{~g} \mathrm{~cm}^{-3}$ ). Porosity varied between 60 and $65 \%$ at the seafloor (Fig. 3C) and was generally lower at Site S60West than at Sites S80 and S100.

A decrease of in situ attenuation with depth was observed at Sites S60West, S80 and S100 (Fig. 3D), with greater values found at Site S80 within the upper $0.8 \mathrm{~m}$ bsf $\left(0.6\right.$ and $0.4 \mathrm{~dB} \mathrm{~m}^{-1}$ $\mathrm{kHz}^{-1}$ ) than at Sites S60 and S100 (approximately 


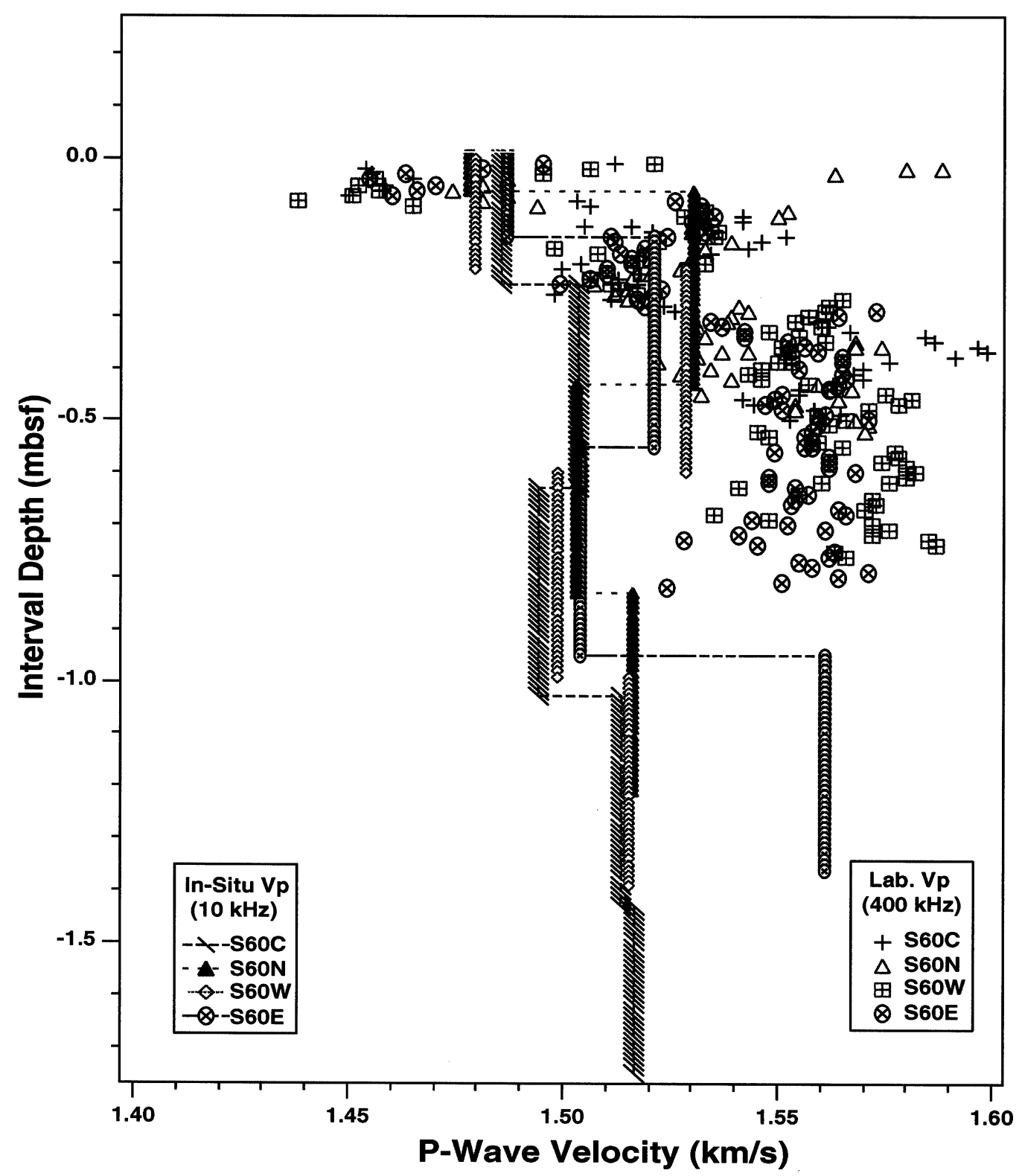

Fig. 4. Variation of sound speed vs. depth measured along the $60 \mathrm{~m}$ isobath showed a high variability of ultrasonic values in the upper $0.5 \mathrm{~m}$ bsf, which were generally faster than corresponding in situ data.

0.09 and $\left.0.05 \mathrm{~dB} \mathrm{~m}^{-1} \mathrm{kHz}^{-1}\right)$. In situ attenuation at S100 increased rapidly between 0.7 and $1.1 \mathrm{~m}$ bsf, from 0.03 to approximately $0.45 \mathrm{~dB} \mathrm{~m}^{-1}$ $\mathrm{kHz}^{-1}$, which correlated with an acoustic sound speed increase from approximately 1480 to $1540 \mathrm{~m}$ $\mathrm{s}^{-1}$. Laboratory ultrasonic attenuation was gener- ally greater than in situ values at all three sites, but did not decrease with depth in a fashion similar to corresponding in situ data (Fig. 3D).

Trends in geoacoustic and bulk properties similar to Site S60West were also found at the other S60 sites (Fig. 4). At all four S60 sites most lab- 

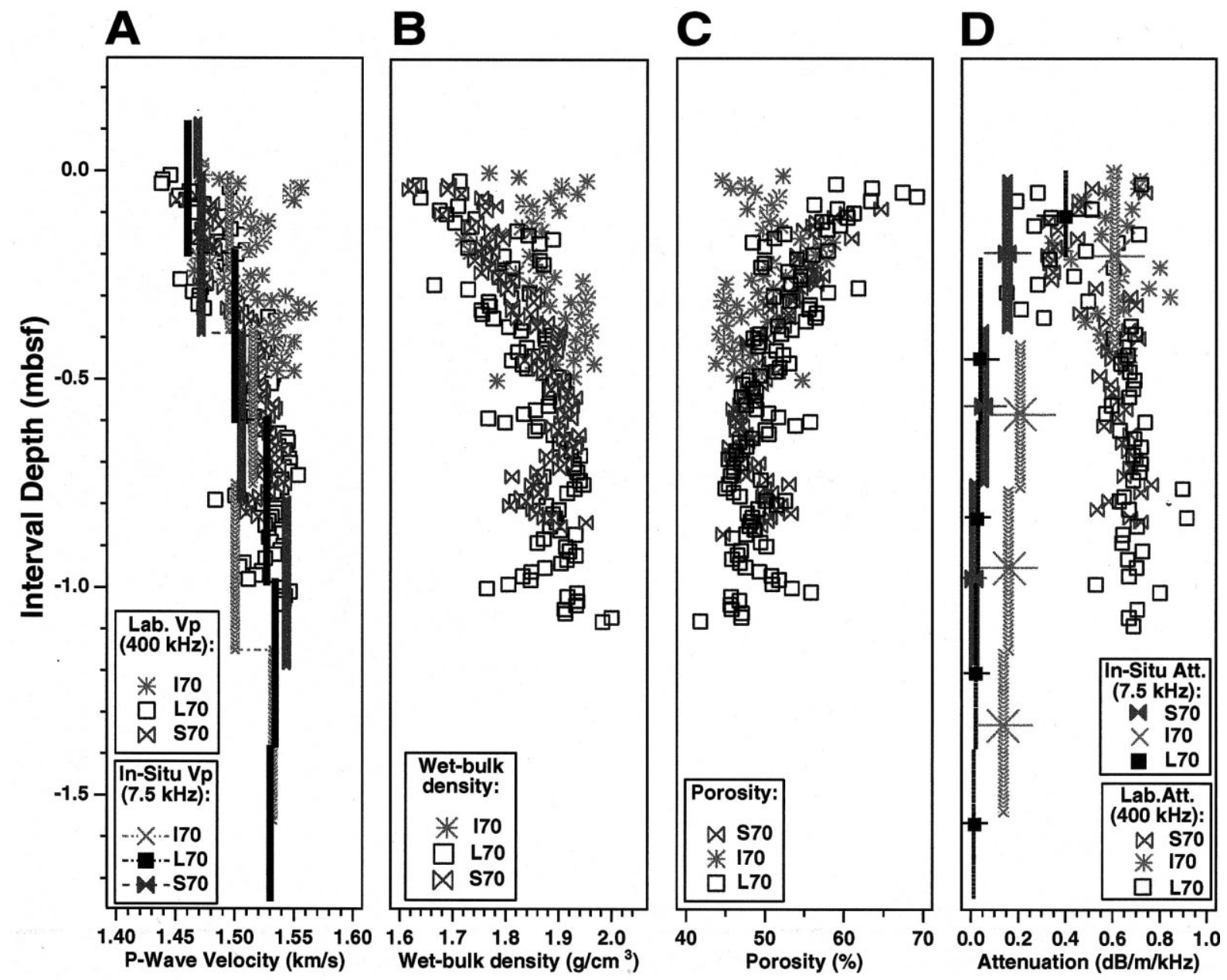

Fig. 5. Along-shelf variation of interval sediment sound speed (A), wet-bulk density (B), porosity (C), and interval attenuation (D) vs. depth on the Eel River shelf. Horizontal error bars on individual attenuation data points were extracted from 10 best-fit inverse models (Frazer et al., 1999). Ultrasonic sound speeds and attenuation were measured in the shipboard laboratory on core samples at $400 \mathrm{kHz}$ every $0.01 \mathrm{~m}$.

oratory ultrasonic sound speeds were faster than corresponding in situ values, with average differences near $35 \mathrm{~m} \mathrm{~s}^{-1}$.

\subsection{Along-shelf properties}

In situ and ultrasonic geoacoustic properties, wet-bulk density, and porosity obtained along the 70-m isobath at Sites I70, L70, and S70 (Fig. 5) were similar to those measured downslope below $60 \mathrm{~m}$ water depth (Fig. 3). Positive gradients of sound speed (Fig. 5A) and wet-bulk den- sity (Fig. 5B) at Sites I70, L70, and S70 were observed within the upper $1.75 \mathrm{~m}$ bsf. In situ sound speed was greatest within the upper $0.4 \mathrm{~m}$ bsf at Site I70, and showed relatively little variation over the entire penetration depth, while corresponding values below $0.6 \mathrm{~m}$ bsf were generally faster at Sites L70 and S70 than at Site I70 (Fig. 5A). In contrast, laboratory ultrasonic sound speed and wet-bulk density at Site I70 exhibited a greater variability than at Sites L70 and S70, especially within the upper $0.4 \mathrm{~m}$ bsf.

In situ attenuation along the lateral transect 
was greater at Site I70 than at Sites L70 and S70 (Fig. 5D). Acoustic attenuation at the three sites varied at the seafloor between 0.2 and $0.65 \mathrm{~dB}$ $\mathrm{m}^{-1} \mathrm{kHz}^{-1}$, and decreased to values between 0.01 and $0.15 \mathrm{~dB} \mathrm{~m}^{-1} \mathrm{kHz}^{-1}$ at maximum penetration depths. In general, in situ attenuation at those three sites was lower than most ultrasonic laboratory values, which varied over small core intervals between 0.15 and $0.75 \mathrm{~dB} \mathrm{~m}^{-1} \mathrm{kHz}^{-1}$ within the upper $0.4 \mathrm{~m}$ bsf. Below that depth, ultrasonic attenuation values remained almost constant, varying between 0.5 and $0.7 \mathrm{~dB} \mathrm{~m}^{-1}$ $\mathrm{kHz}^{-1}$.

\section{Discussion}

\subsection{Geoacoustic properties governed by environmental factors}

A large volume of fluvial sediment is annually transported offshore from the Eel River shelf by currents, swells and tides (e.g., Goff et al., 1999; Ogston and Sternberg, 1999). Along the upper shelf, in water depths to $60 \mathrm{~m}$, fluvial muds from the Eel River watershed are mixed with coarse-grained shelf sediments by hydrodynamic turbulence before they are deposited, eroded and redeposited (Nittrouer and Kravitz, 1995; Drake, 1999). On deeper parts of the shelf, where wind and wave action is reduced, a mixture of finegrained silts and fluvial muds is deposited as a soft sediment body (Wiberg et al., 1996; Wheatcroft et al., 1996, 1997; Goff et al., 1996, 1999). Every decade, on average, during storm events a surplus of muddy sediments is discharged from the Eel River estuary onto the shelf, forming distinct flood deposits in water depths between 40 and $90 \mathrm{~m}$ (Wheatcroft et al., 1996, 1997; Wiberg et al., 1996; Goff et al., 1999). A deposit from 1995 is concentrated north of the Eel River mouth, with approximate maximum thicknesses of $0.07 \mathrm{~m}$ across the $70-$ and $80-\mathrm{m}$ isobaths (Fig. 1). This deposit is characterized by soft fluvial muds intermixed with fine-grained silts and minute amounts of very fine sands (Borgeld et al., 1999; Drake, 1999). Surficial porosity at Sites L70, S70, S80, and S100 up to 70\% (Figs. 3C and
5C) reflects rapid sediment deposition without significant compaction time (Wheatcroft et al., 1996, 1997). It has been suggested that parts of the shelf below $60 \mathrm{~m}$ water depth have been built as a sequence of compacted flood deposits, which have been altered over time by bioturbation and erosion due to bottom currents (Goff et al., 1996, 1999; Cutter and Diaz, 2000). The surficial morphology of this sequence of remnant and more recent deposits provides evidence for the prevalent direction of bottom currents from south to north during storm events, while current directions are reversed in storm-free periods (Cacchione et al., 1999). As a result of these depositional conditions on the Eel margin, geoacoustic and physical properties within the upper $0.4 \mathrm{~m}$ bsf vary more at Sites S60, I70, and S70 than at Sites L70, S80 and S100 (Figs. 3-5). With increasing core depth, compaction of sediments caused in situ and ultrasonic sound speed to increase smoothly at most sites, and a decrease in porosity (Figs. 3-5). At Site S60 high values of sound speed and wet-bulk density, and the recovery of only short gravity cores due to a greater resistance to penetration indicated an increased amount of harder sediment on the upper shelf (Figs. 3 and 4). Consequently, shallower than $60 \mathrm{~m}$ of water depth no cores were retrieved due to the increasing hardness of the sediments. In contrast, longer cores were obtained in softer sediments at Sites S80 and L70, corresponding to lower sound speed and wet-bulk density close to the center of the 1995 flood deposit (Fig. 1).

A steeper negative gradient for in situ attenuation was observed at Sites I70, S80, L70 and S70 than at Sites S60 and S100 over the upper $0.5 \mathrm{~m}$ bsf. For example, at Site S80, no indications of coarse-grained material were detected in the bulk properties (Fig. 3B,C), negating any suggestion of intrinsically more attenuating fine-grained sands as proposed by Hamilton (1972). Leurer (1997) has theoretically asserted that fine-grained cohesive, clay-rich marine sediments can exhibit high attenuation because of viscous absorption mechanisms that are related to squirt flow. We, however, attributed the significant gradient of in situ attenuation with depth not to poroviscoelastic processes (Biot, 1956a,b), but to the presence of 
thin layers in the near surface that are associated with the flood deposit (Wheatcroft et al., 1996, 1997). Thin-bed layering and interface roughness increase scattering of acoustic energy due to multiple reflections within the bed, and cause an energy transfer from the initial pulse into the coda, which then is removed by intrinsic attenuation (Frazer, 1994).

We may have detected an intact thin-bed layer at Site S100 below the maximum depth of present-day biological activity. At this site further off-shore (Fig. 1), very low in situ sound speed, density and attenuation values (Fig. 3A,B,D) were exhibited within the upper $0.7 \mathrm{~m}$ bsf of seafloor, which indicated homogeneously distributed fine silts and clays due to low hydrographic turbulence and strong biological activity. Bioturbation at S100 might have caused a reworking of this particular sediment facies, which can occur on time scales of a few months and destroy near-surface thin-bed layers rapidly within the upper $0.3 \mathrm{~m}$ bsf (e.g., Wheatcroft et al., 1996, 1997; Drake, 1999). Below this homogenized surface-layer, a sediment sequence of sand or compacted mud might have been deposited prior to the flood event, similar to one that was observed at Site O70 (Drake, 1999). At Site S100, such a layer of compacted mud between 0.7 and $1.1 \mathrm{~m}$ bsf may have significantly increased in situ attenuation from 0.03 to $0.45 \mathrm{~dB}$ $\mathrm{m}^{-1} \mathrm{kHz}^{-1}$ (Fig. 3D) and in situ sound speed from $1480 \mathrm{~m} \mathrm{~s}^{-1}$ to $1540 \mathrm{~m} \mathrm{~s}^{-1}$ (Fig. 3A). In contrast to the upper sequence at Site S100, where acoustic and physical properties strongly correlated, no similar gradients in wet-bulk density and porosity were found for this particular sediment sequence (Fig. 3B,C). The effect of compaction alone is unlikely to increase the sound speed of that magnitude, especially considering a sound speed decrease to $1500 \mathrm{~m} \mathrm{~s}^{-1}$ below $1.1 \mathrm{~m} \mathrm{bsf}$. The core length at Site S100 was limited to approximately $1 \mathrm{~m}$, which could be also evident of an increase in sediment strength due to a greater amount of sand or compacted mud within this stratigraphic interval. Unfortunately, we do not possess enough information from post-cruise core studies to determine, which process may have controlled this enigmatic acoustic behavior.

At Site S60, in situ attenuation was expected to be at least as high as at Sites I70, S70 or S80, either caused by stratigraphic scattering from thin-bed layers (Frazer, 1994), grain-size- and overburden pressure-related intergranular friction (Hamilton, 1972), or viscoelastic absorption (Biot, 1956a,b). Instead, we measured comparatively low in situ attenuation (Fig. 3D). We explained this result with a relatively high noise-level that typically contaminated our acoustic records obtained on the upper shelf. Extracting attenuation from acoustic data is much more difficult than velocity, and attenuation estimates are correspondingly more vulnerable to noise than velocity data (Frazer et al., 1999). Ultrasonic attenuation was maximal at Site $\mathrm{S} 60$, and exhibited a significant variability within the upper $0.4 \mathrm{~m}$ bsf. We attributed this to a combination of grain-size-related intrinsic attenuation (friction) and scattering of compressional sound wave energy on heterogeneities at ultrasonic wavelengths (Fig. 3D).

\subsection{Differences between in situ acoustic and laboratory ultrasonic data}

\subsubsection{Sound speed}

A significant difference between in situ and averaged laboratory ultrasonic compressional wave sound speed was measured in a majority of our profiles (Fig. 6A). This result may suggest evidence for dispersion, which describes the frequency dependence of sound speed in anelastic materials, with the expectation that sound speed increases with frequency. The dispersive behavior of elastic wave propagation through porous media was theoretically predicted (Biot, 1956a,b; Kjartansson, 1979), and reported for sound speed in sandy sediments (Barbagelata et al., 1991; Fu, 1998). Other researchers doubt the existence of dispersion in marine sediments or argue that the effect may be so small over a wide frequency band that it can be neglected (Hamilton, 1972; Kibblewhite, 1989; Bowles, 1997; Buckingham, 1997).

Recent compressional wave sound speed measurements in near-surface sandy sediments of Kaneohe Bay, Hawaii, between 20 and $100 \mathrm{kHz}$ showed an increase in values of approximately $25 \mathrm{~m} \mathrm{~s}^{-1}$ (Baffi, 1999). This sound speed increase was not only in agreement with an appropriate 
Biot model, but also close to the maximal difference between in situ and ultrasonic sound speed that we obtained in Eel margin sediments along the $60-\mathrm{m}$ water isobath (Fig. 4). In contrast, finegrained, cohesive surficial sediments investigated in Kaneohe Bay exhibited almost a constant

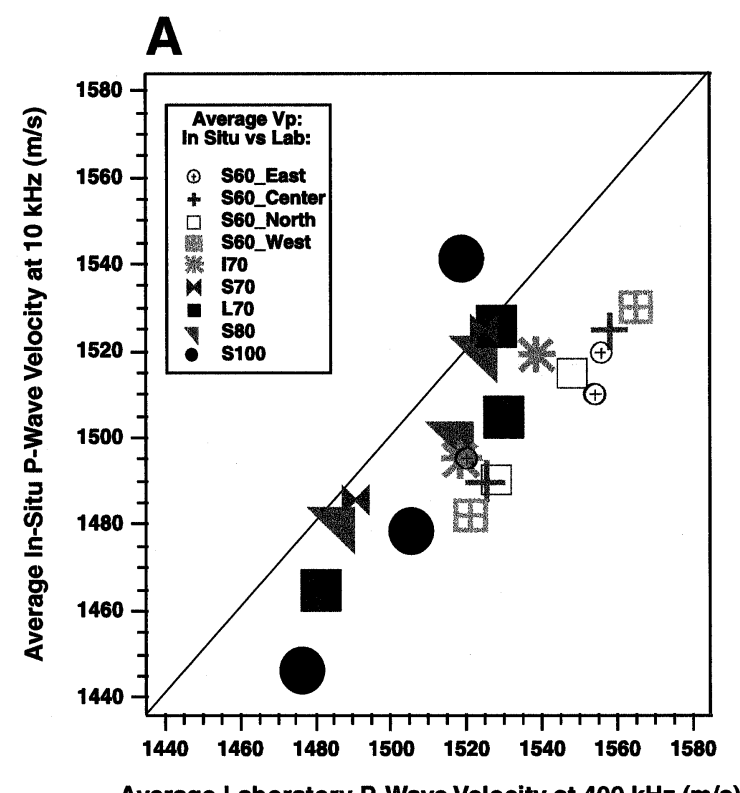

B

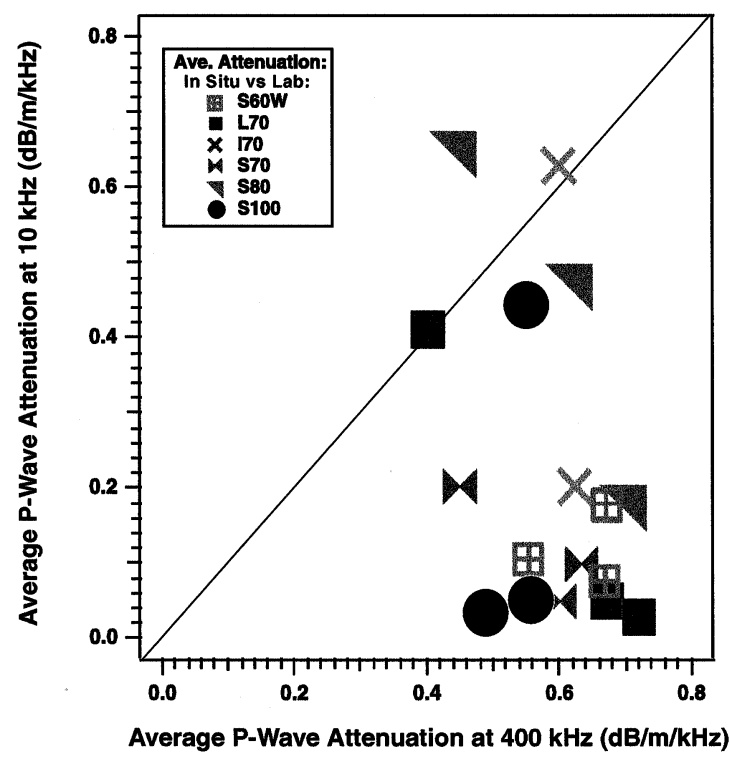

sound speed over the wide frequency band of $100 \mathrm{kHz}$, suggesting non-dispersive attenuation behavior in accordance with the Biot model for this sediment type. Dispersion observed in the present study was greatest at Site S60, but also existed to a lesser extent at the other sites (Fig. 6A). Theoretical constructs (Biot, 1956a,b; Kjartansson, 1979) predict precisely this behavior, with sandier sediments exhibiting greater dispersion.

We do not believe that differences between in situ and ultrasonic sound speed observed in Eel margin sediments were related to velocity anisotropy. This dependence on measurement directivity can be linked to the alignment of platy grains and flattened pores in the bedding plane (Johnston and Christensen, 1995). Following this argument, we would expect that anisotropy would be greatest in fine-grained, cohesive muds below the 60-m isobath, not in less cohesive sediments on the upper shelf, where small amounts of finegrained sands were found (e.g., Drake, 1999).

\subsubsection{Attenuation}

We found larger differences between in situ and laboratory attenuation than for corresponding velocity data (Fig. 6). A substantial majority of in situ attenuation values were much lower than their ultrasonic counterparts averaged over the same seafloor depth interval (Fig. 6B). In situ attenuation was moderately high in the near-surface interval at three sites and tended to decrease steadily downcore at all locations, except at Site S100 (Figs. 3 and 5). Ultrasonic data, on the other hand, exhibited great variability in sediments within the upper $0.4 \mathrm{~m}$ bsf, and stabilized at relatively high values in deeper core sections. Fur-

Fig. 6. Laboratory ultrasonic sound speed was averaged over the same depth intervals as corresponding Lance data (every $0.4 \mathrm{~m}$ ). Averaged ultrasonic laboratory vs. in situ acoustic sound speed (A) showed a greater discrepancy between both values when obtained in relatively coarse-grained than in fine-grained sediments, probably because of dispersion (Biot, 1956a,b). An even more pronounced difference existed in attenuation measured at the two distinct frequencies (B) than for sound speed data (A), which was most likely enhanced by scattering at thin-bed layers and at heterogeneities in the sediment column. 


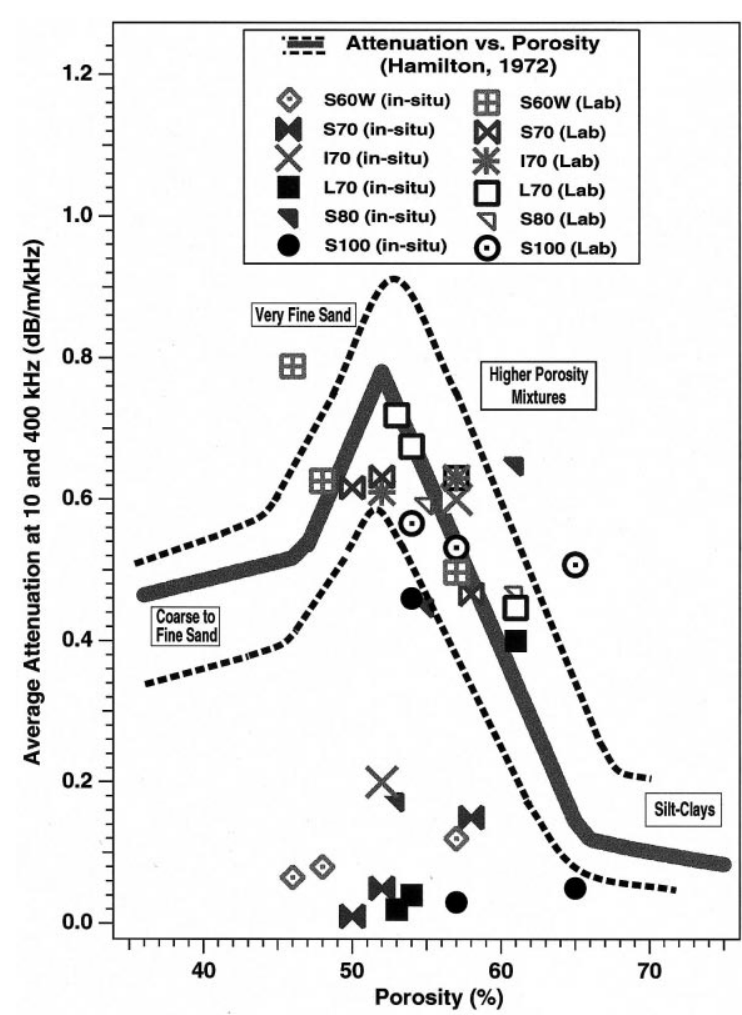

Fig. 7. Porosity vs. attenuation for both the downslope- and along-shelf transect was compared with empirically determined regression fits (gray and dotted lines) from Hamilton (1972). Ultrasonic data from the present study generally matched with Hamilton's data fit, while most in situ attenuation values did not, especially below $0.5 \mathrm{~m}$ bsf. This result was related to compaction, which lowers attenuation with depth due to an enhanced contact between the grains (Hamilton, 1976). High in situ attenuation at S100 below $0.7 \mathrm{~m}$ bsf may be explained with stratigraphic scattering of acoustic sound wave energy at a thin-bed of sand or compacted mud, topped by a homogeneous, soft sediment body.

thermore, averaged ultrasonic attenuation as a function of porosity exhibited a better agreement with relationships first described by Hamilton (1972) than corresponding in situ values (Fig. 7). According to Hamilton (1972) porosity has proven indicative of intrinsic attenuation behavior of marine sandy, silty and clay-rich sediments and rocks because it reflects the number and type of interparticle contacts. Grain size, angularity, area of contact points, permeability, bulk moduli, and shape of pore spaces are some of the many parameters in marine sediments that are related to porosity, and thus to attenuation processes (Biot, 1956a,b; Hamilton, 1971b, 1972; Stoll, 1989). Hamilton (1972) suggested that attenuation in marine sediments is non-dispersive, and primarily controlled by intergranular friction in sands and sandy silts due to a large number of contacts between grains, while in clay-rich cohesive sediments electrochemical forces govern sound wave absorption (Hamilton, 1971a; Meissner and Theilen, 1983).

In contrast to non-dispersive internal friction and electrochemical forces, dispersive absorption mechanisms in marine sediments have been attributed to viscous damping caused by pore fluid motion relative to the frame and individual grains (Biot, 1956a,b; McCann and McCann, 1969; Stoll, 1989). Yamamoto and Turgut (1988) argued that differences in attenuation between acoustic and ultrasonic measurements are caused solely by viscous absorption mechanisms that are strongly dependent on the grain- and pore-size distribution when obtained at frequencies between 5 and $100 \mathrm{kHz}$. Furthermore, their modified Biot model predicted a good match for the same frequency band with Hamilton's empirically determined fit for attenuation values as a function of mean grain size.

We are not, however, convinced that dispersion, as predicted by Biot-Stoll models (e.g., Yamamoto and Turgut, 1988; Leurer, 1997) and concluded from data presented by others (Stoll, 1989; Kibblewhite, 1989; Bowles, 1997; Baffi, 1999) produces differences of the observed magnitude in Eel margin sediments. While attenuation is much more difficult to measure than sound speed because of its sensitivity to noise and transducer response, these limitations should not produce the distinct differences that we see in our data. Only some of our in situ attenuation values matched well with both Hamilton's regression fit (Hamilton, 1972) and with the Biot model of Yamamoto and Turgut (1988) when plotted against mean grain size (Fig. 8), while the majority of in situ and averaged ultrasonic attenuation values did not. We believe that the good correspondence between empirical and theoretical sediment acoustic studies with only some of our geoacoustic data highlight the possibility of dispersive behavior 


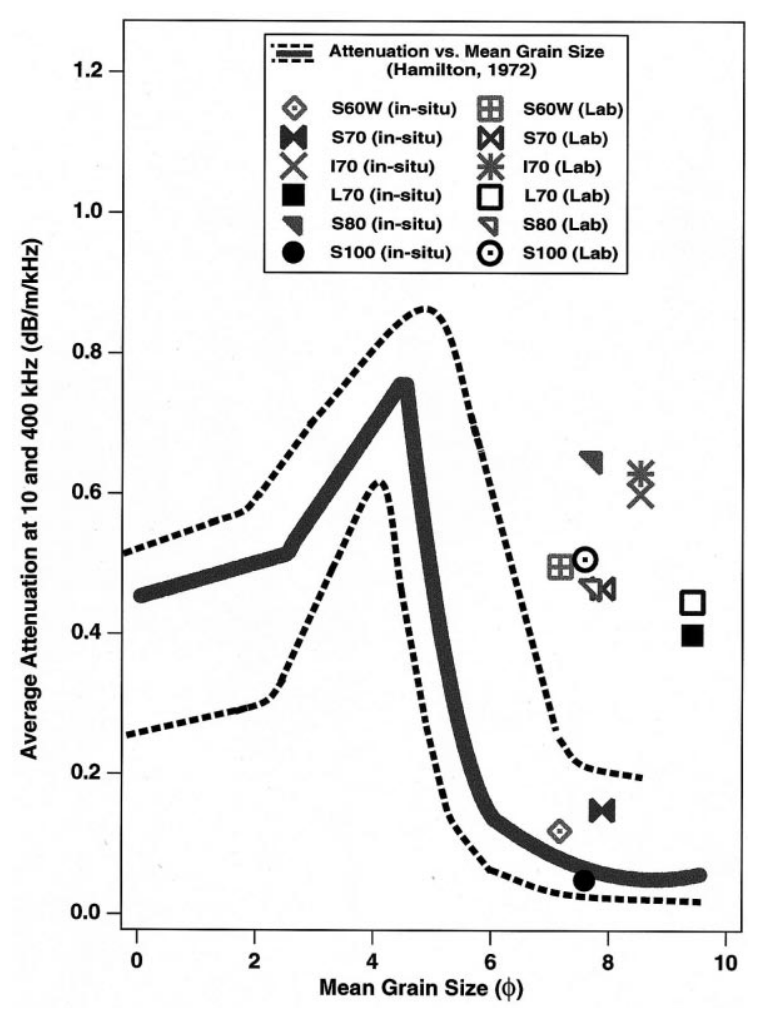

Fig. 8. Most of our in situ and ultrasonic attenuation values did not match with results from empirical studies (Hamilton, 1972) or theoretical predictions (Yamamoto and Turgut, 1988), probably because of stratigraphic scattering of acoustic sound energy at thin-beds (Frazer et al., 1999), or due to backscattering of ultrasonic waves at sediment heterogeneities.

(Figs. 3-8). Nevertheless, we hypothesize that much of the unexplained disparity between in situ and ultrasonic attenuation data and model values can be related to stratigraphic and grainsize-related scattering (Vidmar, 1984; Richardson and Briggs, 1993, 1996). In heterogeneous Eel margin sediments our ultrasonic signals had a wavelength of about $0.003 \mathrm{~m}$, whereas in situ wavelengths were closer to $0.15 \mathrm{~m}$. Grain-cluster sizes and sediment disturbances due to bioturbation, and the presence of random shell fragments were measured to be on the order of our ultrasonic wavelength (Cutter and Diaz, 2000). We argue that particle scattering contributed strongly to the absorption of ultrasonic sound wave energy. In contrast, near-surface in situ attenuation may have been more sensitive to stratigraphic scattering along bed boundaries for sediment layers with a thickness less than our used acoustic wavelengths (Frazer, 1994). For a few depth intervals an agreement might have existed between in situ and laboratory data by pure coincidence when the effects of layering and high-frequency scattering produced roughly the same effect on acoustic and ultrasonic signals at the two different wavelengths.

Laboratory ultrasonic attenuation values obtained in Eel margin sediments did not decrease with depth like corresponding in situ data below approximately $0.4 \mathrm{~m}$ bsf (Figs. 3 and 5). If grainsize-related scattering below $0.4 \mathrm{~m}$ bsf did not control our ultrasonic attenuation profiles, a growing number of grain contacts might have caused a higher rate of intergranular friction (Hamilton, 1976). Hamilton's empirical results (1976) suggest a decrease of attenuation with depth in coarse-grained sediments (higher strength of frame compared to increase in friction) and an increase in attenuation in soft sediments because muds and silts compact more easily than sands (friction increases faster than frame strength). Conversely, an increase in rigidity and bulk frame strength with overburden pressure may have reduced attenuation as a counterbalance to frictional processes (Hamilton, 1976), which would comply with our in situ attenuation profiles (Figs. 3D and 5D). It should be noted that Hamilton's observation describes an attenuation-depth dependence over several tens or hundreds of meters of subsurface depth, and may not be simply transferred to our data set, which describes only the upper 1 or $2 \mathrm{~m}$ of seafloor depth. Overall our ultrasonic attenuation data exhibited greater variability near the seafloor surface, and appeared to either increase slightly with depth in both coarsegrained (surficial porosity between 42 and 55\%) and fine-grained sediments (near-surface porosity higher than $55 \%$ ), or remained almost constant. According to Hamilton (1976) our ultrasonic attenuation profiles would reflect the dominant effect of friction caused by compaction. In contrast, in situ attenuation decreased with depth, which possibly was the result of (1) the effects of overburden pressure on the frame moduli overcoming 
the tendency of increased attenuation through compaction-related friction, and (2) particularly where we found intervals of relatively high nearsurface in situ attenuation, the presence of thinbeds may have caused greater stratigraphic scatter than in deeper, more homogeneous sections.

\section{Conclusions}

Geoacoustic and physical property measurements conducted on the Eel margin in California revealed the spatial and vertical distribution of different sediment types between the 60- and $100-\mathrm{m}$ isobaths. Greatest variability in our data was found along the upper shelf where a highenergy environment forms a heterogeneous sediment composite of coarse- and fine-grained sediments. This sediment heterogeneity of the upper shelf changes into a more homogeneous sediment composition in the shore-normal direction towards deeper waters. Fluvial sediments are transported in suspension from the coastal watershed by prevailing currents in a northerly direction during short-term storm events until they are deposited further offshore. During storm-free periods sediments are transported in a southerly direction and across the shelf by bottom and tidally induced currents. Long- and short-term processes affect both erosion and deposition cycles of surficial sediments due to bottom currents, subsequent bioturbation and compaction of previously deposited sediments. In concert these factors favor the development of thin-bed layers within the upper $0.4 \mathrm{~m}$ bsf along the middle and lower shelf area below $60 \mathrm{~m}$ of water depth. High surficial in situ attenuation and a subsequent decrease of values with depth probably occurred whenever stratigraphic layering within the top $0.4 \mathrm{~m}$ bsf may have generated strong impedance contrasts or an enhanced interface roughness. If the presence of thin beds increased in situ attenuation, then layering may be most pronounced across the most recent flood deposit between the 70- and $90-\mathrm{m}$ isobaths. U1trasonic attenuation was generally greater than in situ values and maximal in sediments of high sand content (S60). We linked this result to dispersive viscoelastic absorption mechanisms and to non-dispersive grain-size-related friction. In addition, ultrasonic attenuation was most likely overprinted by scattering from unidentified inhomogeneities in the sediment column that were of the size of ultrasonic wavelengths. Furthermore, ultrasonic attenuation at greater core depths differed from near-surface values by showing less variation, and in contrast to in situ values exhibited no decrease with depth. This discrepancy in laboratory and in situ attenuation data may have been enhanced by core sample disturbances, pore water release during coring, alterations of the effective stress regime, or a differential sensitivity of in situ and ultrasonic sound wave propagation to dewatering and compaction processes of unconsolidated sediments. Horizontal layering was most likely detected by obtaining in situ attenuation with measurements in the vertical penetration direction. Our analyses of in situ acoustic and laboratory ultrasonic data together with physical properties acquired in cohesive, fine-grained Eel margin sediments strongly suggest that investigators must exercise great caution when applying laboratory values of sound speed and attenuation to in situ situations. Sound speed dispersion appears to have a measurable effect on the relationship between the two data types, particularly in sediments that contain a greater amount of sand. Scattering occurs on entirely different scales, and interval attenuation at in situ frequencies behaves differently than small-scale, high-frequency measurements. Clearly an understanding of sediment microstructure and makeup of all sediment components will be critical for future attempts to model the acoustic behavior of the seafloor.

\section{Acknowledgements}

This work was supported by the Ocean Acoustics Program of the Office of Naval Research, and the Naval Research Laboratory. We gratefully acknowledge the help of the crew onboard the R/V Wecoma, Oregon State University. Thoughtful suggestions by Joe Kravitz, Aubrey Anderson and 
one unidentified reviewer contributed to significant improvements of the original manuscript. J.B. Swimmer provided additional helpful editorial comments.

\section{References}

Baffi, S., 1999. Velocity and Attenuation Dispersion in Carbonate Sediments, Kaneohe Bay, Oahu. Unpublished MS thesis, University of Hawaii, Manoa, 126 pp.

Barbagelata, A., Richardson, M.D., Miaschi, B., Muzi, E., Guerrini, P., Troiano, L., Akal, T., 1991. ISSAMS: An insitu sediment acoustic measurement system. In: Hovem, J.M. (Ed.), Shear Waves in Marine Sediments. Kluwer, Dordrecht, pp. 305-312.

Biot, M.A., 1956a. Theory of propagation of elastic waves in a fluid-saturated porous solid, I. Low frequency range. J. Acoust. Soc. Am. 28, 168-178.

Biot, M.A., 1956b. Theory of propagation of elastic waves in a fluid-saturated porous solid, II. Higher frequency range. J. Acoust. Soc. Am. 28, 179-191.

Borgeld, J.C., Hughes Clarke, J.E., Goff, J.A., Mayer, L.A., Curtis, J.A., 1999. Acoustic backscatter of the 1995 flood deposit on the Eel shelf. Mar. Geol. 154, 197-210.

Bowles, F.A., 1997. Observations on attenuation and shearwave velocity in fine-grained, marine sediments. J. Acoust. Soc. Am. 101 (5), 1-13.

Boyce, R.E., 1976. Definitions and laboratory techniques of compressional sound velocity parameters and wet-water content, wet-bulk density and porosity parameters by gravimetric and gamma-ray attenuation techniques. Init. Rep. DSDP 33, 931-951.

Briggs, K.B., Richardson, M.D., Young, D.K., 1985. Variability in geoacoustic and related properties of subsurface sediments from the Venezuela Basin, Caribbean Sea. Mar. Geol. 68, 73-106.

Bromirski, P., Frazer, L.N., Duennebier, F.K., 1995. The Q-Gram method: Q from instantaneous phase. Geophys. J. Int. 120, 73-86.

Buckingham, M.J., 1997. Theory of acoustic attenuation, dispersion, and pulse propagation in unconsolidated granular materials including marine sediments. J. Acoust. Soc. Am. 102 (5), 2579-2596.

Cacchione, D.A., Drake, D.E., 1990. Shelf sediment transport: an overview with applications to the northern California Shelf. In: Le Mehaute, B., Hanes, D. (Eds.), The Sea, Vol. 9, Wiley, pp. 729-773.

Cacchione, D.A., Wiberg, P.L., Lynch, J., Irish, J., Traykovski, P., 1999. Estimates of suspended-sediment flux and bedform activity on the inner portion of the Eel continental shelf. Mar. Geol. 154, 83-97.

Cutter, G.R., Diaz, R.J., 2000. Biological alteration of physically structured flood deposits on the Eel margin, northern California. Cont. Shelf Res. 20, 235-253.

Drake, D.E., 1999. Temporal and spatial variability of the sediment grain-size distribution on the Eel shelf: the flood layer of 1995. Mar. Geol. 154, 169-182.

Drake, D.E., Cacchione, D.A., 1985. Seasonal variation in sediment transport in the Russian River shelf, California. Cont. Shelf Res. 4, 495-514.

Frazer, L.N., 1994. A pulse in a binary sediment. Geophys. J. Int. 118, 75-93.

Frazer, L.N., Fu, S.S., Wilkens, R.H., 1999. Seabed sediment attenuation profiles from a moveable subbottom acoustic vertical array. J. Acoust. Soc. Am. 106, 120-130.

Fu, S.S., 1998. The Experimental Study of In-Situ Acoustic Properties in Marine Sediments. Unpublished PhD thesis, University of Hawaii, Manoa, 146 pp.

Fu, S.S., Wilkens, R.H., Frazer, L.N., 1996a. Acoustic Lance: new in-situ velocity profiles. J. Acoust. Soc. Am. 99, 234 242.

Fu, S.S., Wilkens, R.H., Frazer, L.N., 1996b. In-situ velocity profiles in gassy sediments: Kiel Bay. Geo-Mar. Lett. 16, 249-253.

Goff, J.A., Mayer, L.A., Hughes Clarke, J.E., Pratson, L.F., 1996. Swath mapping on the continental shelf and slope: the Eel River Basin, northern California. Oceanography 9, 178182.

Goff, J.A., Orange, D.L., Mayer, L.A., Hughes Clarke, J.E., 1999. Detailed investigation of continental shelf morphology using a high-resolution swath sonar survey: the Eel margin, northern California. Mar. Geol. 154, 255-269.

Hamilton, E.L., 1971a. Elastic properties of marine sediments. J. Geophys. Res. 76, 579-604.

Hamilton, E.L., 1971b. Prediction of in-situ acoustic and elastic properties of marine sediments. Geophysics 36, 266-283.

Hamilton, E.L., 1972. Compressional wave attenuation in marine sediments. Geophysics 37, 620-646.

Hamilton, E.L., 1976. Sound attenuation as a function of depth in the seafloor. J. Acoust. Soc. Am. 59, 528-535.

Jannsen, D.H., Voss, J., Theilen, F., 1985. Comparison of methods to determine $\mathrm{Q}$ in shallow marine sediments from vertical reflection seismograms. Geophys. Prospect. 33, 479497.

Johnston, J.E., Christensen, N.I., 1995. Seismic anisotropy of shales. J. Geophys. Res. 100 (4), 5991-6003.

Kibblewhite, A.C., 1989. Attenuation of sound in marine sediments: a review with emphasis on new low-frequency data. J. Acoust. Soc. Am. 86, 716-738.

Kjartansson, E., 1979. Constant Q-wave propagation and attenuation. J. Geophys. Res. 84, 4737-4748.

Leurer, K.C., 1997. Attenuation in fine-grained marine sediments: extension of the Biot-Stoll model by the 'effective grain model' (EGM). Geophysics 62, 1465-1479.

McCann, C., McCann, D.M., 1969. The attenuation of compressional waves in marine sediments. Geophysics 34, 882892.

Meissner, R., Theilen, F., 1983. Attenuation of seismic waves in sediments. Proc. 11th World Petroleum Congress 2, pp. 363-379.

Nittrouer, C.A., 1999. STRATAFORM: overview of its design and synthesis of its results. Mar. Geol. 154, 3-12. 
Nittrouer, C.A., Kravitz, J.H., 1995. Integrated continental margin research to benefit ocean and earth sciences. EOS, Trans. Am. Geophys. Union 76, 121-126.

Nittrouer, C.A., Kravitz, J.H., 1996. Strataform: a program to study the creation and interpretation of sedimentary strata on continental margins. Oceanography 9, 146-152.

O'Connell, R.J., Budianski, B., 1978. Measures of attenuation in dissipative media. Geophys. Res. Lett. 5, 5-8.

Ogston, A.S., Sternberg, R.W., 1999. Sediment-transport events on the northern California continental shelf. Mar. Geol. 154, 69-82.

Orange, D.L., 1999. Tectonics, sedimentation, and erosion in northern California: submarine geomorphology and sediment preservation potential as a result of three competing processes. Mar. Geol. 154, 369-382.

Richardson, M.D., 1986. Spatial variability of surficial shallow water sediment geoacoustic properties, In: Akal, T., Berkson, J.M. (Eds.), Meeting SACLANT ASW Research Center Symposium, La Spezia, Italy. Plenum Press, New York, pp. 527-536.

Richardson, M.D., Briggs, K.B., 1993. On the use of acoustic impedance values to determine sediment properties. Proc. I.O.A. 15, 15-24.

Richardson, M.D., Briggs, K.B., 1996. In-situ and laboratory geoacoustic measurements in soft mud and hard-packed sand sediments: implications for high-frequency acoustic propagation and scattering. Geo-Mar. Lett. 16, 196-203.

Richardson, M.D., Briggs, K.B., 1997. In-situ, shallow-water sediment geoacoustic properties. Int. Conf. Shallow-Water Acoustics, Beijing, April 21-25, pp. 163-170.

Richardson, M.D., Young, D.K., 1980. Geoacoustic models and bioturbation. Mar. Geol. 38, 205-218.

Richardson, M.D., Young, D.K., Briggs, K.B., 1983. The effects of hydrodynamic and biological processes on sediment geoacoustic properties in Long Island Sound, U.S.A. Mar. Geol. 52, 201-226.

Richardson, M.D., Briggs, K.B., Bentley, S.J., Orsi, T.H.,
2002. The effects of biological and hydrodynamic processes on physical and acoustic properties of sediments off the Eel River, California. Mar. Geol., this issue.

Sommerfield, C.K., Nittrouer, C.A., 1999. Modern accumulation rates and a sediment budget for the Eel shelf: a flooddominated depositional environment. Mar. Geol. 154, $227-$ 241.

Stoll, R.D., 1989. Sediment Acoustics. In: Bhattacharji, S., Friedman, G.M., Neugebauer, H.J., Seilacher, A. (Eds.), Lecture Notes in Earth Sciences, 26. Springer-Verlag, Berlin.

Tarantola, A., 1987. Inverse Problem Theory. Elsevier, Amsterdam, $647 \mathrm{pp}$.

Tonn, R., 1989. The computation of the seismic quality factor Q: a comparison of various techniques. EOS, Trans. Am. Geophys. Union 70, 391.

Vidmar, P.J., 1984. Linked sets of acoustical processes and geoacoustic profiles describing the interaction of sound with a class of seafloor structures. In: Page, N. (Ed.), Acoustics and the Seabed. Proceedings of Institute of Acoustics, Underwater Acoustics Group Conference, Bath.

Wheatcroft, R.A., Borgeld, J.C., Born, R.S., Drake, D.E., Leithold, E.L., Nittrouer, C.A., Sommerfield, C.K., 1996. The anatomy of a flood deposit. Oceanography 9, 158-162.

Wheatcroft, R.A., Sommerfield, C.K., Drake, D.E., Borgeld, J.C., Nittrouer, C.A., 1997. Rapid and widespread dispersal of flood sediment on the northern Californian margin. Geology $25,163-166$.

Wiberg, P.L., Cacchione, D.A., Sternberg, R.W., Wright, L.D., 1996. Linking sediment transport and stratigraphy on the continental shelf. Oceanography 9, 153-157.

Wilkens, R.H., Richardson, M.D., 1998. The influence of gas bubbles on sediment acoustic properties: in-situ, laboratory, and theoretical results from Eckernförde Bay, Baltic Sea. Cont. Shelf Res. 18, 1859-1892.

Yamamoto, T., Turgut, A., 1988. Acoustic wave propagation through porous media with arbitrary pore size distributions. J. Acoust. Soc. Am. 83, 1744-1751. 